\title{
Reversed Spatial Asymmetries between El Niño and La Niña and Their Linkage to Decadal ENSO Modulation in CMIP3 Models
}

\author{
JiN-Yi Yu AND SEON TAE KIM \\ Department of Earth System Science, University of California, Irvine, Irvine, California
}

(Manuscript received 11 January 2011, in final form 7 April 2011)

\begin{abstract}
This study examines preindustrial simulations from Coupled Model Intercomparison Project, phase 3 (CMIP3), models to show that a tendency exists for El Niño sea surface temperature anomalies to be located farther eastward than La Niña anomalies during strong El Niño-Southern Oscillation (ENSO) events but farther westward than La Niña anomalies during weak ENSO events. Such reversed spatial asymmetries are shown to force a slow change in the tropical Pacific Ocean mean state that in return modulates ENSO amplitude. CMIP3 models that produce strong reversed asymmetries experience cyclic modulations of ENSO intensity, in which strong and weak events occur during opposite phases of a decadal variability mode associated with the residual effects of the reversed asymmetries. It is concluded that the reversed spatial asymmetries enable an ENSO-tropical Pacific mean state interaction mechanism that gives rise to a decadal modulation of ENSO intensity and that at least three CMIP3 models realistically simulate this interaction mechanism.
\end{abstract}

\section{Introduction}

The El Niño-Southern Oscillation (ENSO) undergoes decadal and interdecadal variations in its frequency, intensity, and propagation pattern (e.g., Wang and Wang 1996; An and Wang 2000; Fedorov and Philander 2000; Timmermann 2003; An and Jin 2004; Yeh and Kirtman 2004; and many others). Earlier studies considered decadal ENSO variability to be forced by decadal variability in the extratropical Pacific Ocean via ocean subduction, thermocline ventilation, or atmospheric teleconnections (e.g., McCreary and Lu 1994; Gu and Philander 1997; Wang and Weisberg 1998; Zhang et al. 1998; Barnett et al. 1999; Pierce et al. 2000; McPhaden and Zhang 2002). Later studies suggested that decadal ENSO variability could originate internally within the tropics (e.g., Penland and Sardeshmukh 1995; Knutson et al. 1997; Eckert and Latif 1997; Kirtman and Schopf 1998; Timmermann and Jin 2002; Timmermann 2003; Newman et al. 2003; Yeh and Kirtman 2004; Newman 2007). Interactions between ENSO and the tropical Pacific mean state have been suggested as one of the tropics-origin mechanisms for decadal ENSO

Corresponding author address: Dr. Jin-Yi Yu, Dept. of Earth System Science, University of California, Irvine, Irvine, CA 92697-3100. E-mail: jyyu@uci.edu variability (e.g., Rodgers et al. 2004; Yeh and Kirtman 2004; Schopf and Burgman 2006; Dewitte et al. 2007; Sun and Yu 2009; Choi et al. 2009). Sun and Zhang (2006) conducted numerical experiments with and without ENSO using a coupled model to show that ENSO works as a basin-scale mixer to affect the time-mean thermal stratification in the upper-equatorial Pacific. Rodgers et al. (2004) and An and Jin (2004) suggested that, because of the nonlinearity in the ENSO dynamics, asymmetries exist in the intensity, frequency, or spatial structures between the warm (El Niño) and cold (La Niña) phases of the ENSO cycle. Strong El Niño events tend to reach a larger intensity than strong La Niña events (Hannachi et al. 2003; An and Jin 2004; Duan et al. 2008; Frauen and Dommenget 2010; Su et al. 2010). Also, strong El Niño events tend to be located more in the eastern Pacific, whereas strong La Niña events tend to be located more in the central Pacific (Monahan 2001; Hsieh 2004; Rodgers et al. 2004; Schopf and Burgman 2006; Sun and Yu 2009). Because of these asymmetries, the positive and negative anomalies associated with the El Niño and La Niña phases may produce a nonzero residual effect on the time-mean state of the tropical Pacific. Yeh and Kirtman (2004) and Rodgers et al. (2004) showed that the mean state change associated with decadal ENSO variability is one of the leading modes of tropical Pacific decadal variability in 
their models. These studies indicate that El Niño-La Niña asymmetries provide a mechanism for ENSO to influence the tropical Pacific mean state.

The suggestion that ENSO can act as a forcing to the tropical Pacific mean state was further used by Sun and $\mathrm{Yu}(2009)$ to postulate that a 10-15-yr modulation cycle of ENSO intensity can result from an ENSO-mean state interaction mechanism. They argued that a spatial asymmetry between El Niño and La Niña enables the ENSO cycle (i.e., an El Niño phase plus a La Niña phase) to gradually shift the tropical Pacific mean state from a state that sustains strong ENSO activity to a state that sustains weak ENSO activity. A key element in their mechanism is that the spatial asymmetry between weak El Niño and weak La Niña is reversed from the asymmetry between strong El Niño and strong La Niña. In the strong ENSO period of the 10-15-yr modulation cycle, strong El Niño is located in the eastern tropical Pacific and strong La Niña is located in the central tropical Pacific. In the weak ENSO period of the cycle, weak El Niño is located in the central Pacific and weak La Niña is located in the eastern Pacific. The reversed spatial asymmetries enable the ENSO to force the tropical Pacific mean state in opposite ways between the strong and weak ENSO regimes, acting as a restoring force to push the mean state back and forth between states that sustain strong and weak ENSO intensities. The mean state changes associated with the modulation cycle appears as one of the leading modes of the decadal sea surface temperature (SST) variations in the tropical Pacific. It was noticed that the last three strongest El Niño events occurred at an interval of about 10-15 yr in 1972/73, 1982/ 83, and 1997/98. The ENSO-tropical Pacific mean state interaction mechanism proposed by Sun and $\mathrm{Yu}$ (2009) can be useful for the prediction of extreme ENSO events if it proves to be correct. Their mechanism was constructed on the basis of analyses of historical data, including SST information from the global monthly Extended Reconstructed Sea Surface Temperature dataset, version 2 (ERSST.v2; Smith and Reynolds 2004), and the Hadley Centre Sea Ice and Sea Surface Temperature dataset, version 1 (HadISST1; Rayner et al. 2003), during the period 1880-2006. The relatively short length of the SST datasets includes only a limited number of strong and weak ENSO events for analyses; therefore, a further examination of the ENSO-mean state interaction mechanism should make use of the extended integrations provided by coupled atmosphere-ocean general circulation models (CGCMs).

In this study, we examine the preindustrial simulations produced by 19 Coupled Model Intercomparison Project, phase 3 (CMIP3; Meehl et al. 2007), CGCMs to determine 1) if the reversed asymmetries can also be found in CMIP3 models, 2) if the reversed asymmetries are indeed associated with decadal tropical Pacific mean state variations and cyclic ENSO modulations, and 3) which CMIP3 models reasonably simulate the ENSOmean state interaction mechanism and are best suited for furthering the understanding of this mechanism.

\section{Data}

Preindustrial simulations produced by 19 CMIP3 models are analyzed. Their integration lengths range from 100 to $500 \mathrm{yr}$, with a median of $350 \mathrm{yr}$. At the time of writing, detailed information on the CMIP3 preindustrial integrations could be found online (http://www-pcmdi.llnl.gov/ ipcc/model_documentation/ipcc_model_documentation. php). For comparison, observed SSTs from the ERSST V3b (Smith et al. 2008) and HadISST (Rayner et al. 2003) over 1870-2009 are used. Monthly anomalies are computed by removing long-term seasonal monthly means and the trend.

\section{Results}

To determine if the CMIP3 models simulate the ENSOtropical Pacific interaction mechanism, the associations among three elements need to be examined: the spatial asymmetries between El Niño and La Niña, tropical Pacific decadal variability, and decadal modulations in ENSO intensity. We found that all but three \{Geophysical Fluid Dynamics Laboratory Climate Model, version 2.0 (GFDL CM2.0); Institute of Numerical Mathematics Coupled Model, version 3.0 (INM-CM3.0); and Model for Interdisciplinary Research on Climate 3.2, high-resolution version [MIROC3.2(hires)] $\}$ of the CMIP3 models have their peak ENSO intensity during the extended winter season from October to March (not shown), and thus we averaged the Niño-3.4 index for the extended winter to represent the ENSO intensity. For the three models that do not have their peak ENSO intensity in the winter, their Niño-3.4 indices are averaged during their respective peak seasons, which are June-July-August for GFDL CM2.0 and May-June-July for both INM-CM3.0 and MIROC3.2(hires). These seasons are also used for these three models in the other analyses reported in this study. For the other 16 CMIP3 models, their analyses are always performed for the extended winter. We first identified ENSO events as those whose normalized Niño-3.4 index exceeds \pm 0.3 standard deviation. The identified events are then ranked from the strongest to the weakest separately for El Niño and for La Niña. The top $N \%$ of the ranked events are considered to be the strong events, and the bottom $N \%$ are considered to be the weak events. This selection method results in four groups: strong El Niño, 
(a) For strong ENSO

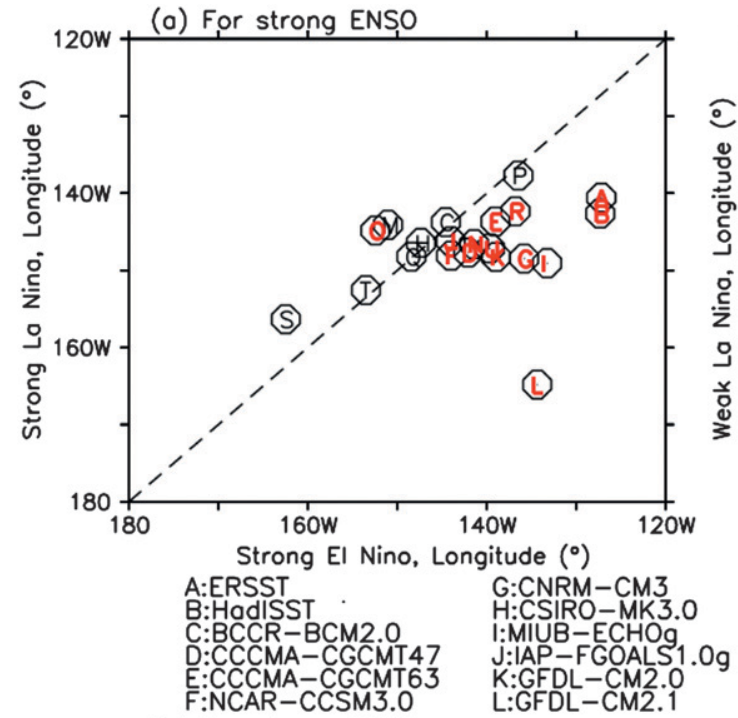

(c) For strong ENSO

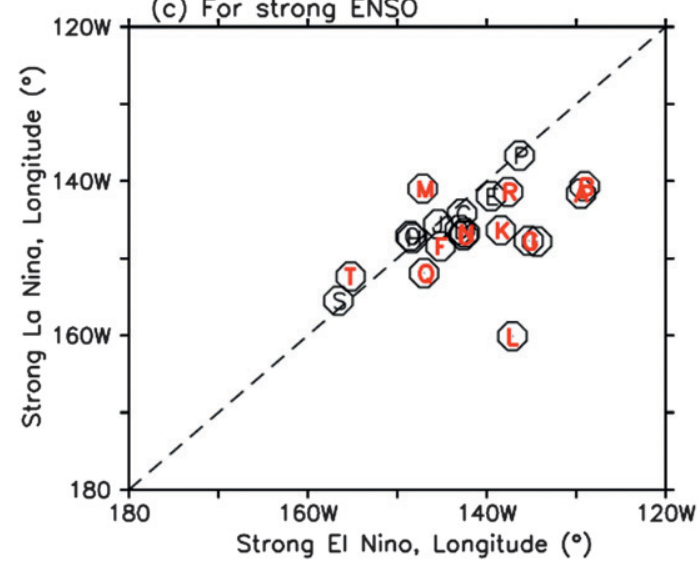

(b) For weok ENSO

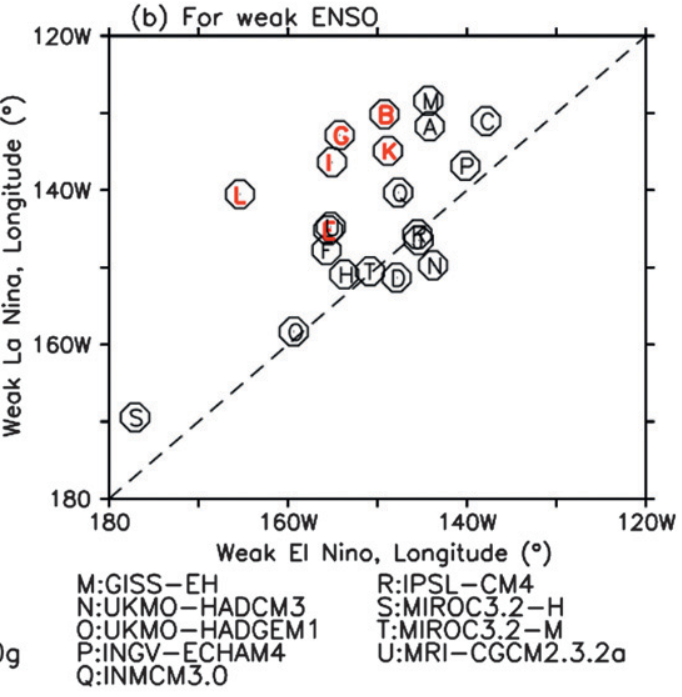

(d) For weak ENSO

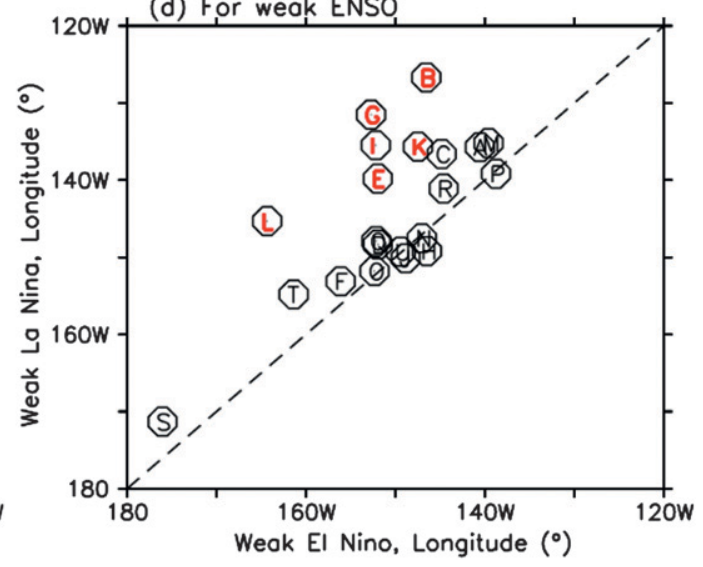

FIG. 1. Scatterplots of the central longitudes of the composite SST anomalies for (a),(c) strong El Niños and La Niñas and (b),(d) weak El Niños and La Niñas. The ENSO events are selected on the basis of the extreme (top) $10 \%$ and (bottom) $20 \%$. Red points indicate the central location difference between El Niño and La Niña is significant at the $90 \%$ level using a Student's $t$ test.

strong La Niña, weak El Niño, and weak La Niña. SST composites are then constructed for each group. The central location of the composite SST anomalies is then determined using a "center of mass" method as follows:

$$
X_{\text {center }}=\frac{\int_{120 \mathrm{E}}^{80 \mathrm{~W}} x \operatorname{SSTA}(x) d x}{\int_{120 \mathrm{E}}^{80 \mathrm{~W}} \operatorname{SSTA}(x) d x},
$$

where $x$ is the longitude and SSTA is the composite SST anomalies averaged between $10^{\circ} \mathrm{N}$ and $10^{\circ} \mathrm{S}$. When the central longitudes (i.e., $X_{\text {center}}$ ) are calculated for the composites of El Niño, only grids with positive SST anomalies are used. Similarly, only grids with negative SST anomalies are used to calculate the central longitudes of the La Niña composites.
The El Niño-La Niña asymmetry is quantified as the central longitude of El Niño minus the central longitude of La Niña. We tried the above procedure with $N=10$, $20,30,40$, and 50 and found that the asymmetries increase sharply when $N$ is reduced to 20 or 10 for the observations and the models. This sensitivity test indicates that the spatial asymmetries are best shown by comparing the extreme $10 \%$ and $20 \%$ of the El Niño and La Niña events. Results presented in this study are produced based on the extreme $10 \%$ of the events, unless stated otherwise.

The scatter diagram in Fig. 1 shows the central longitudes of the composite El Niño and La Niña SST anomalies calculated from the CMIP3 simulations and the observations. The dashed line indicates where the central location of El Niño would be the same as that of La Niña. Points below this line indicate positive asymmetries, in which El Niño is located farther eastward than 

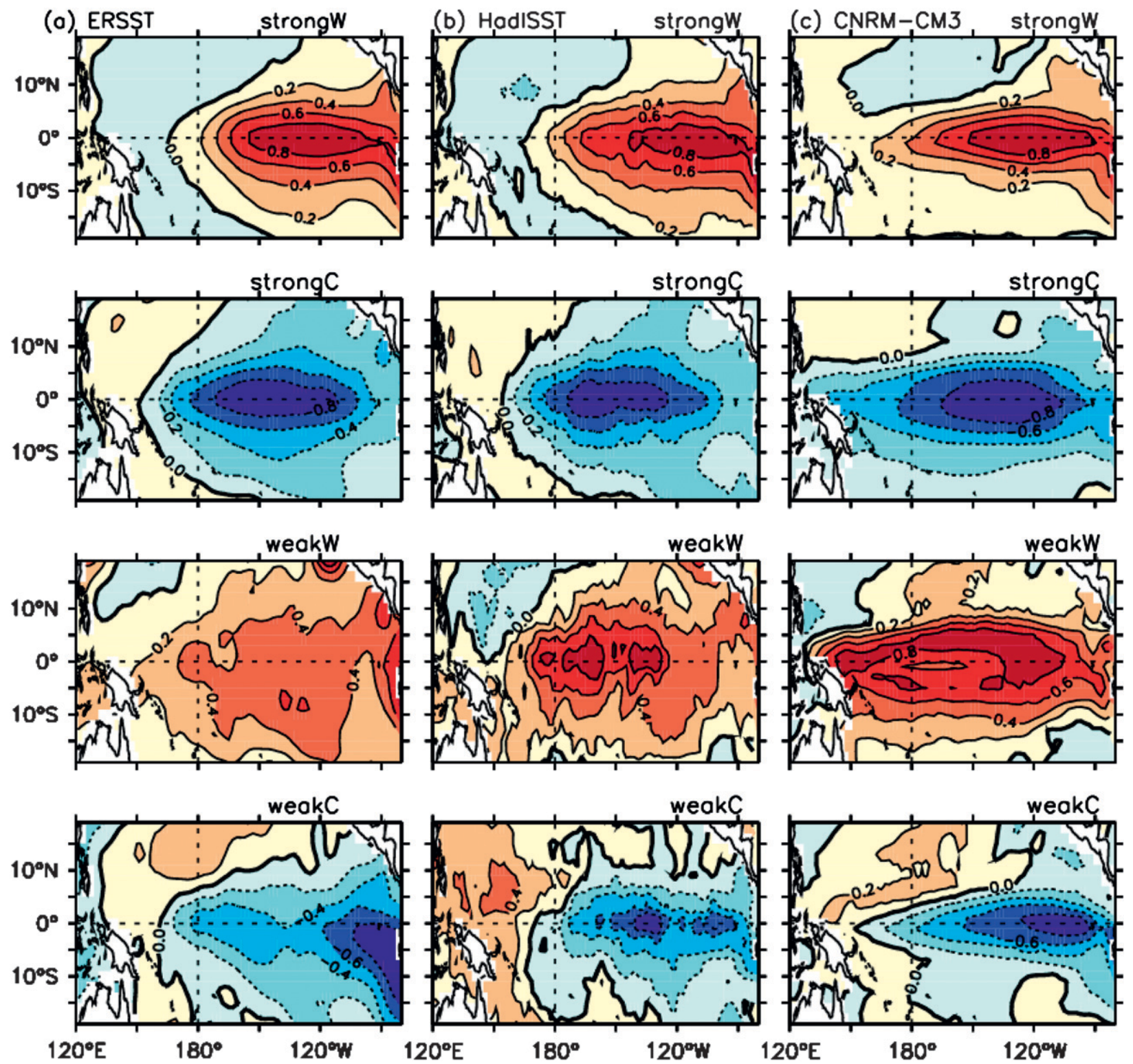

FIG. 2. SST anomalies composited for (rows from top to bottom) strong El Niños, strong La Niñas, weak El Niños, and weak La Niñas calculated from (a) ERSST, (b) HadISST, (c) CNRM-CM3, (d) MIUB-ECHOg, (e) GFDL CM2.0, and (f) GFDL CM2.1. The composite SST anomalies are scaled by the largest value in the composite. Contour intervals are 0.2 .

La Niña. Points above the dashed line represents negative asymmetries with El Niño located more westward than La Niña. Asymmetries significant at the $90 \%$ level according to a Student's $t$ test are colored red. Figure 1a shows that positive asymmetries appear in the observations (points A and B) for the strong ENSO group; SST anomalies are centered at $127^{\circ} \mathrm{W}$ for strong El Niños and at $143^{\circ} \mathrm{W}$ for strong La Niñas. The El Niño-La Niña asymmetry is characterized by a $16^{\circ}$ longitudinal displacement of the SST anomalies, which is statistically significant at the $90 \%$ level. Figure $1 \mathrm{~b}$ shows that, in the weak ENSO group, the asymmetry is reversed with points $\mathrm{A}$ and $\mathrm{B}$ moved to the other side of the dashed line. The El NiñoLa Niña asymmetry is statistically significant in the HadISST dataset (point B) but not in the ERSST dataset (point A). In HadISST, the composite weak El Niño is located in the central Pacific $\left(149^{\circ} \mathrm{W}\right)$ and the composite weak La Niña is located in the eastern Pacific $\left(130^{\circ} \mathrm{W}\right)$. The observed El Niño-La Niña asymmetry for the weak ENSO group is about $-19^{\circ}$. This analysis confirms the finding by Sun and $\mathrm{Yu}$ (2009), who used a different analysis method, that spatial asymmetries between El Niño and La Niña 
(d) MIUB-ECHOg strongW
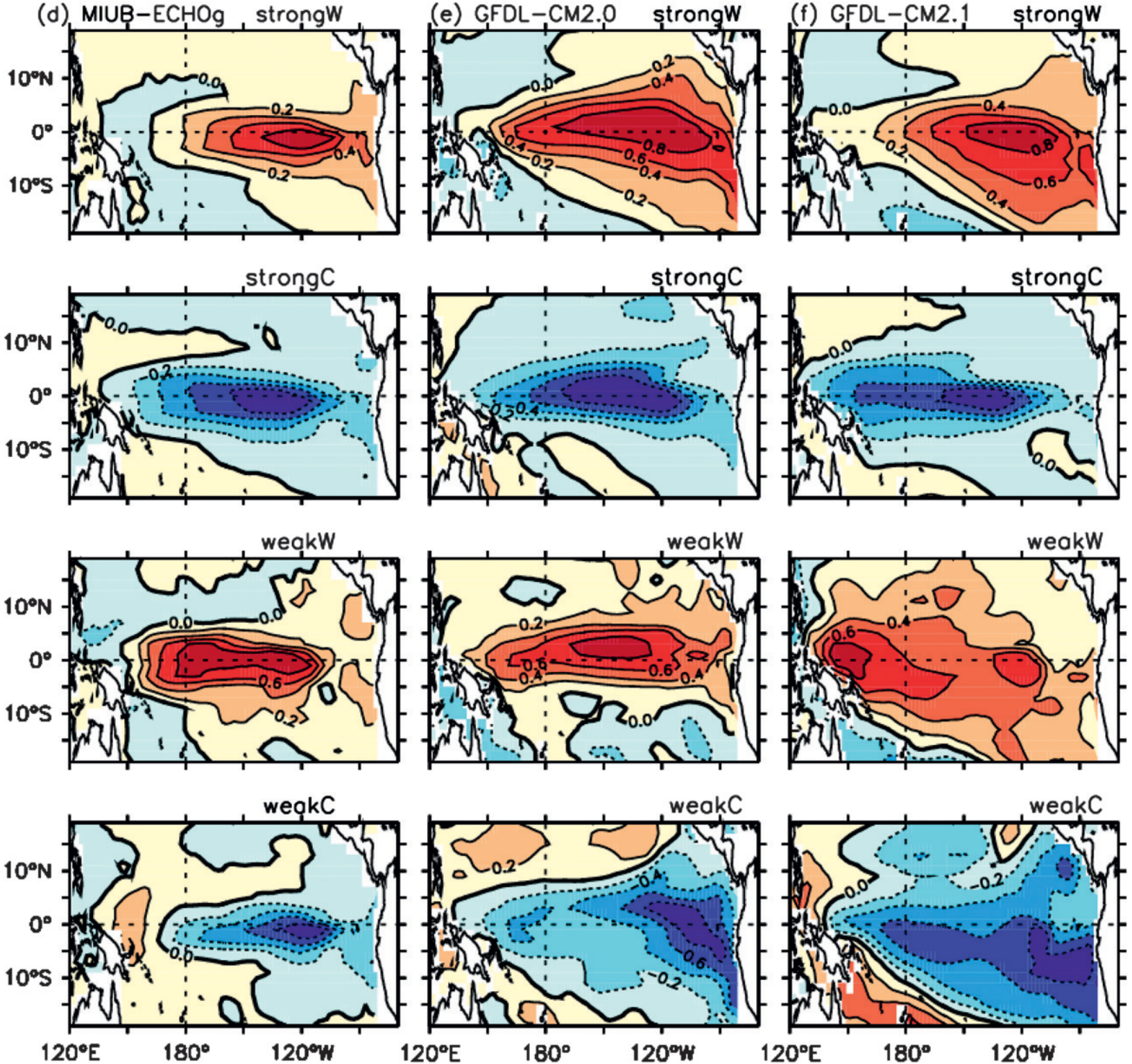

$120^{\circ} \mathrm{E}$

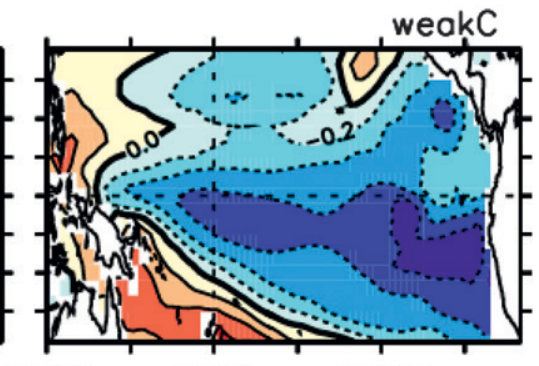

$120^{\circ} \mathrm{E} \quad 180^{\circ} \quad 120^{\circ} \mathrm{W}$

FIG. 2. (Continued)

exist not only in strong but also in weak ENSOs. Our study further indicates that in the observations the spatial asymmetry between weak El Niño and La Niña (i.e., -19²) is comparable to the asymmetry between strong El Niño and La Niña (i.e., $16^{\circ}$ ).

For the CMIP3 models, 11 models produce statistically significant positive asymmetries for the strong ENSO group (Fig. 1a) and 5 models produce significant negative asymmetries for the weak ENSO group (Fig. 1b). Therefore, there are five CMIP3 models that produce the statistically significant reversed spatial asymmetries between strong and weak ENSOs: the Canadian Centre for Climate Modelling and Analysis (CCCma) coupled
GCM (CGCM-T63) (point E); the Centre National de Recherches Météorologiques Coupled Global Climate Model, version 3 (CNRM-CM3) (point G); Meteorology Institute of the University of Bonn ECHAM4 Hamburg Ocean Primitive Equation model (MIUB-ECHOg) (point I); GFDL CM2.0 (point K); and GFDL CM2.1 (point L). To test the sensitivity of this result to the selection criteria used for the strong and weak ENSO groups, we repeated the calculation with the extreme $20 \%$ of the ENSO events. As shown in Figs. 1c and 1d, only the CCCma CGCM-T63 fails to pass the significance test for spatial asymmetry between strong El Niño and La Niña, although it still shows a significant asymmetry between weak El Niño 
and La Niña. We conclude that at least four CMIP3 models produce the reversed asymmetries with statistical significance: CNRM-CM3, MIUB-ECHOg, GFDL CM2.0, and GFDL CM2.1. Their spatial asymmetries vary from $\pm 10^{\circ}$ to $\pm 19^{\circ}$, comparable to the observed. Figure 2 shows the composite SST anomalies from these four models and the observations for strong El Niño, strong La Niña, weak El Niño, and weak La Niña. To focus on the spatial asymmetries, the composite anomalies are scaled by their respective largest values. Figure 2 confirms that the tropical Pacific SST anomalies are located farther to the west for weak El Niños and to the east for weak La Niñas and the other way around for strong El Niños and strong La Niñas.

The residual effect on the tropical Pacific time mean state resulting from the spatial asymmetries can be assessed by adding together the scaled composite SST anomalies of El Niño and La Niña, as shown in Fig. 3a for strong El Niño and La Niña. The residuals calculated from the weak El Niño and La Niña (not shown) are similar to those shown in Fig. 3a, but with opposite sign. Figure 3a shows that the observed residual effect is characterized by a zonal SST dipole with positive anomalies in the eastern Pacific and negative anomalies in the central Pacific. Similar SST dipole patterns appear in all four of the CMIP3 models that produce significant reversed asymmetries, although the exact locations of the anomaly centers vary among the models. We also analyzed the residual effects for the other 15 CMIP3 models (not shown) and found no similar, major dipole patterns. It should be mentioned that a zonal dipole pattern can appear in the Meteorological Research Institute Coupled General Circulation Model, version 2.3.2a (MRI CGCM2.3.2a), if the residual effect is calculated from the nonscaled composite SST anomalies, which suggests that the dipole residual pattern in this model is probably a result of intensity asymmetries, rather than spatial asymmetries, between El Niño and La Niña.

According to the ENSO-tropical Pacific interaction mechanism of Sun and Yu (2009), the reversed spatial asymmetries should enable ENSO to modify the tropical Pacific mean state and should result in a mode of tropical Pacific decadal variability that resembles the residual effect. We examined the decadal SST variability in the tropical Pacific by applying an empirical orthogonal function (EOF) analysis to 10-yr low-pass-filtered SST anomalies from the simulations and observations. The second EOF modes from HadISST and ERSST (the top two panels of Fig. 3b) are found to be characterized by zonal SST dipole patterns between the eastern and central tropical Pacific. Although noticeable differences exist, the east-west contrast features of the EOF2 patterns roughly resemble the residual effect of the El Niño-La
Niña asymmetries shown in Fig. 3a. To quantify the similarity between the residual pattern and the EOF mode, we calculated the pattern correlation between the two patterns over the tropical Pacific region $\left(20^{\circ} \mathrm{S}-20^{\circ} \mathrm{N}\right.$, $\left.120^{\circ} \mathrm{E}-80^{\circ} \mathrm{W}\right)$. As shown in Table 1 , the observed residual pattern of Fig. 3a has a larger pattern correlation with the EOF2 mode of the decadal SST variability than with the EOF1 mode. The correlation with EOF2 is 0.30 for the ERSST data and 0.37 for the HadISST. We notice that the similarity is increased further when the EOF analysis is applied to the bandpass (10-20 yr)-filtered SST anomalies that sharpen the focus to the decadal portion of the SST variability only. As shown in Fig. 3c, the EOF2 calculated from the 10-20-yr-filtered SST anomalies is more similar to the residual pattern shown in Fig. 3a for both the ERSST and HadISST datasets. Their pattern correlation increases to 0.62 for ERSST and to 0.63 for HadISST.

For the CMIP3 models, we find that three of the four models that produce the significant reversed asymmetries have a second EOF (fourth-sixth panels in Fig. 3b) resembling their residual effect patterns. As shown in Table 1, the three models (MIUB-ECHOg, GFDL CM2.0, and GFDL CM2.1) have a pattern correlation between the EOF2 mode and the residual pattern of greater than 0.6. For the CNRM-CM3 (third panel in Fig. 3b), it is the first EOF mode that has a spatial pattern similar to the residual effect, with a pattern correlation of 0.57 , but the outof-phase relation between the eastern and central Pacific is less obvious in this EOF. For the rest of the 15 CMIP3 models (not shown), only 2 models have a zonal SST dipole in their leading EOF modes: CCCma CGCM3.1T63, and MRI-CGCM2.3.2a. As mentioned, the SST dipole pattern can be produced in the residuals of MRICGCM2.3.2a as a result of intensity asymmetries between El Niño and La Niña. The CCCMA CGCM3.1-T63 is able to produce statistically significant reversed asymmetries for the extreme $10 \%$ of its ENSO events but fails to pass the significance test for the extreme $20 \%$ events. Our CMIP3 model analyses, therefore, support the notion that the reversed spatial asymmetries are one important contributor to tropical Pacific decadal variability.

Last, we examined the linkage between the leading mode of tropical Pacific decadal variability and the decadal ENSO modulation. Following Sun and Yu (2009), we used an "envelope function" to quantify the slow modulation of ENSO intensity. To construct the envelope function, the Niño-3.4 index was first squared and then filtered with a 10-yr cutoff low-pass filter to highlight the decadal variations. The resulting quantity was multiplied by 2 in recognition of the fact that the "power" of a pure harmonic oscillation of arbitrary frequency averaged over one certain period is just one-half times 
(a) Residual For Strong

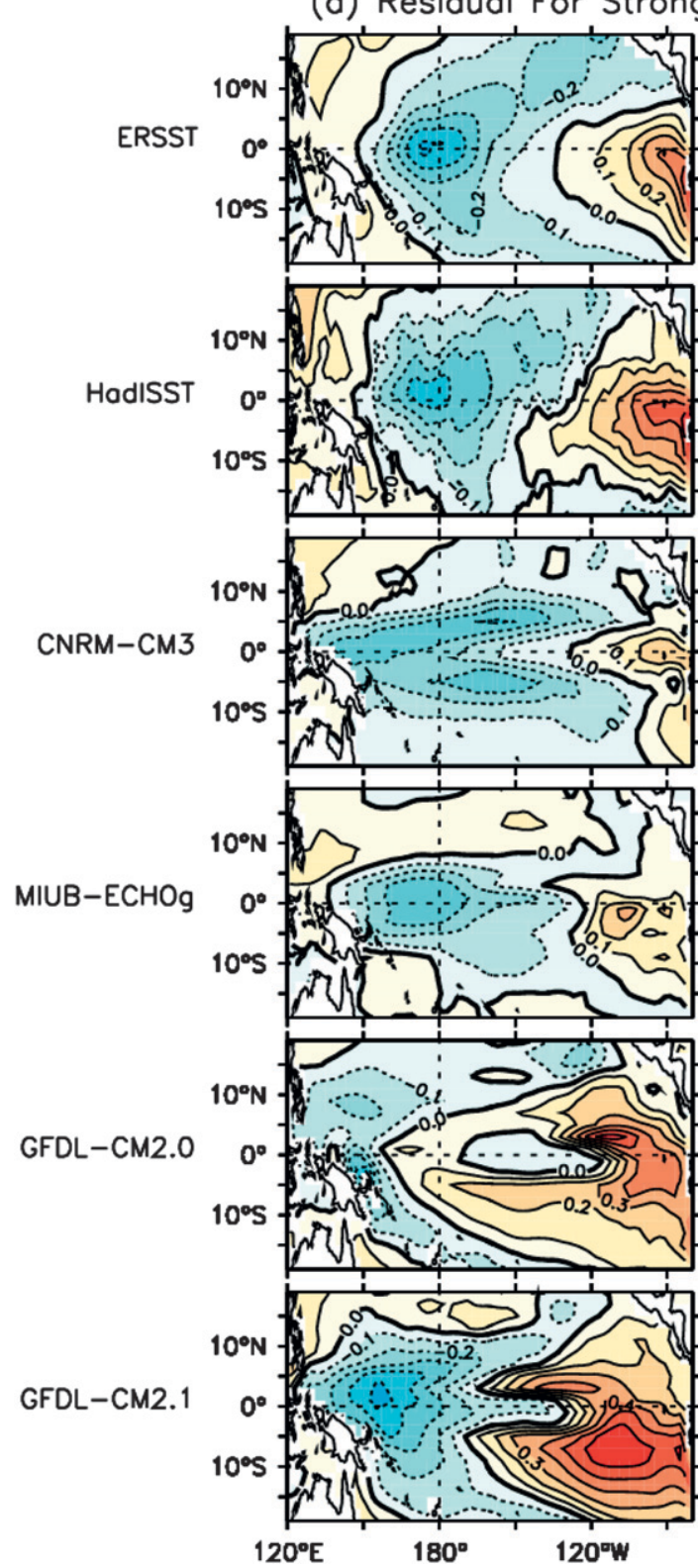

(b) EOF (10yr low pass)
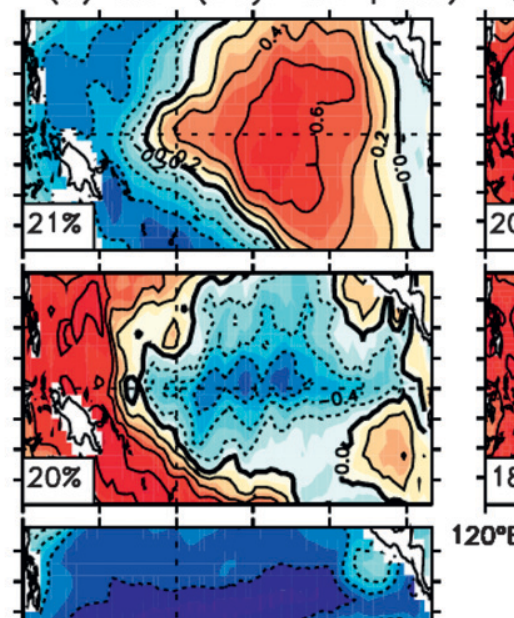

(c) EOF (Band-pass)

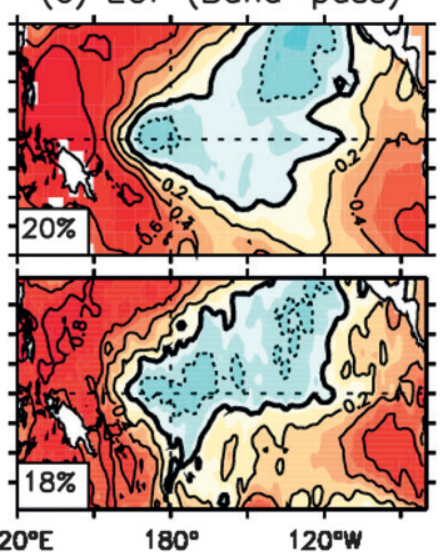

FIG. 3. Spatial patterns of (a) the residual SST anomalies for strong ENSO events and (b) the EOF modes for the 10-yr low-pass-filtered seasonally averaged SST anomalies. In (b), the pattern of the second EOF is shown for ERSST, HadISST, MIUB-ECHOg, GFDL CM2.0, and GFDL CM2.1 and the pattern of the first EOF is shown for CNRM-CM3. (c) The second EOF modes obtained from 10-20-yr bandpass-filtered anomalies for ERSST and HADISST. The percentage of variance explained by each EOF mode is shown in the bottomleft corner of the panels in (b) and (c). Contour intervals are 0.1 for (a) and 0.2 for (b) and (c).

the squared intensity of the oscillation (Nakamura and Wallace 1990). The resulting series is defined as the envelope function (hereinafter ENVF) of the Niño-3.4 index. The square root of this time series represents the "true" amplitude of the decadal ( $>10 \mathrm{yr}$ ) modulation.

We calculated the lead-lag correlation between the square-rooted ENVF and the principal components of both EOF1 and EOF2 of the tropical Pacific decadal variability for the 19 CMIP3 models. The results are displayed in Fig. 4 by ranking the models from the one producing the largest correlation to the one producing the smallest correlation. The figure shows that the first five models produce larger correlation coefficients than the rest of the models. The first three of them are MIUBECHOg, GFDL CM2.0, and GFDL CM2.1, all of which are the models that produce significant reversed 
TABLE 1. Pattern correlations between the residual SST anomalies for strong ENSO events and EOF modes for the 10-yr lowpass-filtered and seasonally averaged SST anomalies from CMIP3 models and observations. For all of the CMIP3 models and observations, the SST anomalies are averaged for the extended winter season (October-March) except GFDL CM2.0 (June-July-August), INM-CM3.0 (May-June-July), and MIROC3.2(hires) (May-JuneJuly). The four models that produce the reversed El Niño-La Niña asymmetries are shown in boldface.

\begin{tabular}{|c|c|c|c|}
\hline & \multirow[b]{2}{*}{ Obs/models } & \multicolumn{2}{|c|}{$\begin{array}{c}\text { Pattern correlations between } \\
\text { residuals (strong events) } \\
\text { and EOFs }\end{array}$} \\
\hline & & EOF1 & EOF2 \\
\hline $\mathrm{a}$ & ERSST & 0.11 & 0.30 \\
\hline $\mathrm{b}$ & HADISST & 0.00 & 0.37 \\
\hline $\mathrm{c}$ & BCCR-BCM2.0 & 0.37 & 0.09 \\
\hline d & CCCma CGCM3.1-T47 & 0.14 & 0.09 \\
\hline e & CCCma CGCM3.1-T63 & 0.19 & 0.20 \\
\hline $\mathrm{f}$ & NCAR CCSM3 & 0.18 & 0.46 \\
\hline $\mathrm{g}$ & CNRM-CM3 & 0.57 & 0.13 \\
\hline $\mathrm{h}$ & CSIRO-MK3 & 0.46 & 0.26 \\
\hline $\mathrm{i}$ & MIUB-ECHOg & 0.32 & 0.86 \\
\hline j & IAP-FGOALS1.0g & 0.04 & 0.64 \\
\hline $\mathrm{k}$ & GFDL CM2.0 & 0.26 & 0.66 \\
\hline 1 & GFDL CM2.1 & 0.59 & 0.83 \\
\hline $\mathrm{m}$ & GISS-EH & 0.05 & 0.61 \\
\hline $\mathrm{n}$ & UKMO-HADCM3 & 0.06 & 0.12 \\
\hline o & UKMO-HADGEM1 & 0.62 & 0.48 \\
\hline $\mathrm{p}$ & INGV-ECHAM4 & 0.09 & 0.18 \\
\hline $\mathrm{q}$ & INM-CM3.0 & 0.30 & 0.36 \\
\hline $\mathrm{r}$ & IPSL-CM4 & 0.05 & 0.11 \\
\hline s & MIROC3.2(hires) & 0.17 & 0.29 \\
\hline $\mathrm{t}$ & MIROC3.2(medres) & 0.35 & 0.00 \\
\hline $\mathrm{u}$ & MRI-CGCM2.3.2a & 0.43 & 0.01 \\
\hline
\end{tabular}

asymmetries and a leading tropical Pacific decadal variability resembling the residual pattern of the asymmetries. The largest correlation coefficients produced by these three models are all greater than 0.6, with the decadal EOF2 mode, and with the square-rooted ENVF either leading the decadal EOF mode or at zero lag. GFDL CM2.0 and GFDL CM2.1 produce the largest correlation coefficient of 0.68 and 0.82 , respectively, when their square-rooted ENVF leads their EOF2 mode by $1 \mathrm{yr}$, and MIUB-ECHOg produces the largest correlation coefficient of 0.92 at zero lag. The tendency for the squarerooted ENVF to lead the principal component of the decadal EOF mode is an indication of the decadal ENSO modulation forcing to the decadal mean state variability of the tropical Pacific. Figures 3 and 4 together suggest that the decadal modulation cycle can be linked to slow changes in the tropical Pacific mean state via the residual effect. The fourth largest correlation coefficient in Fig. 4 is produced by CNRM-CM3. Consistent with the results shown in Fig. 3, the square-rooted ENVF of CNRM$\mathrm{CM} 3$ has the largest correlation of 0.62 with the EOF1 of the decadal variability when the square-rooted ENVF leads the EOF1 by 2 yr. The Institute of Atmospheric Physics Flexible Global Ocean-Atmosphere-Land System Model, gridpoint version 1.0 (IAP-FGOALS1.0g), also produces a large correlation coefficient of 0.61 at zero lag, but neither its residual pattern nor its EOF2 shows a zonal SST contrast pattern. The rest of the 14 models produce small correlation coefficients between their square-rooted ENVF and their leading two decadal EOFs.

We also examine the overall intensity of the decadal ENSO modulation in the CMIP3 models by calculating the standard deviation of the square-rooted ENVF. The results are ranked in Fig. 5 from the model with the strongest modulation to the model with the weakest modulation. It shows that the top six CMIP3 models that produce the strongest standard deviation of the squarerooted ENVF (i.e., strong decadal ENSO modulation) are IAP-FGOALS1.0g; MIUB-ECHOg; GFDL CM2.1; CNRM-CM3; Bjerknes Centre for Climate Research Bergen Climate Model, version 2 (BCCR-BCM2.0); and GFDL CM2.0. Four of these models are the ones that produced the reversed spatial asymmetries. This result indicates that the CMIP3 models that produce stronger reversed spatial asymmetries also have a tendency to produce stronger decadal ENSO modulations. To further verify that the occurrences of weak and strong ENSO events are indeed closely linked to the decadal mean state variability of the tropical Pacific, we plot in Fig. 6 the occurrence time of the extreme $10 \%$ of the strong and weak ENSO events from the MIUB-ECHOg, GFDL CM2.0, and GFDL CM2.1 on the principal components of their decadal EOF2 modes. These three models have so far been identified to produce 1) significant reversed asymmetries between El Niño and La Niña, 2) high resemblance between the residual pattern from the asymmetries and a leading mode of tropical Pacific decadal variability, and 3) a large decadal ENSO modulation. CNRM-CM3 could also be included in this group of the models, except that its leading decadal EOF (i.e., its EOF1) does not show an obvious zonal contrast pattern. In Fig. 6, a red circle indicates a strong ENSO event occurring at that particular year of the model simulation, and the red circle is plotted on the principal component (the black line) of the decadal EOF2 mode at that particular year. Weak ENSO events are indicated by blue circles in the figure. To be consistent with the ENSO-tropical Pacific interaction mechanism, we should hope to see most of the strong ENSO events (i.e., the red circles) to occur in the positive phase of the principal component and most of the weak ENSO events (i.e., the blue circles) to occur in the negative phase. Figure 6 shows that, for all three models, most of the strong ENSO events (red circles) 

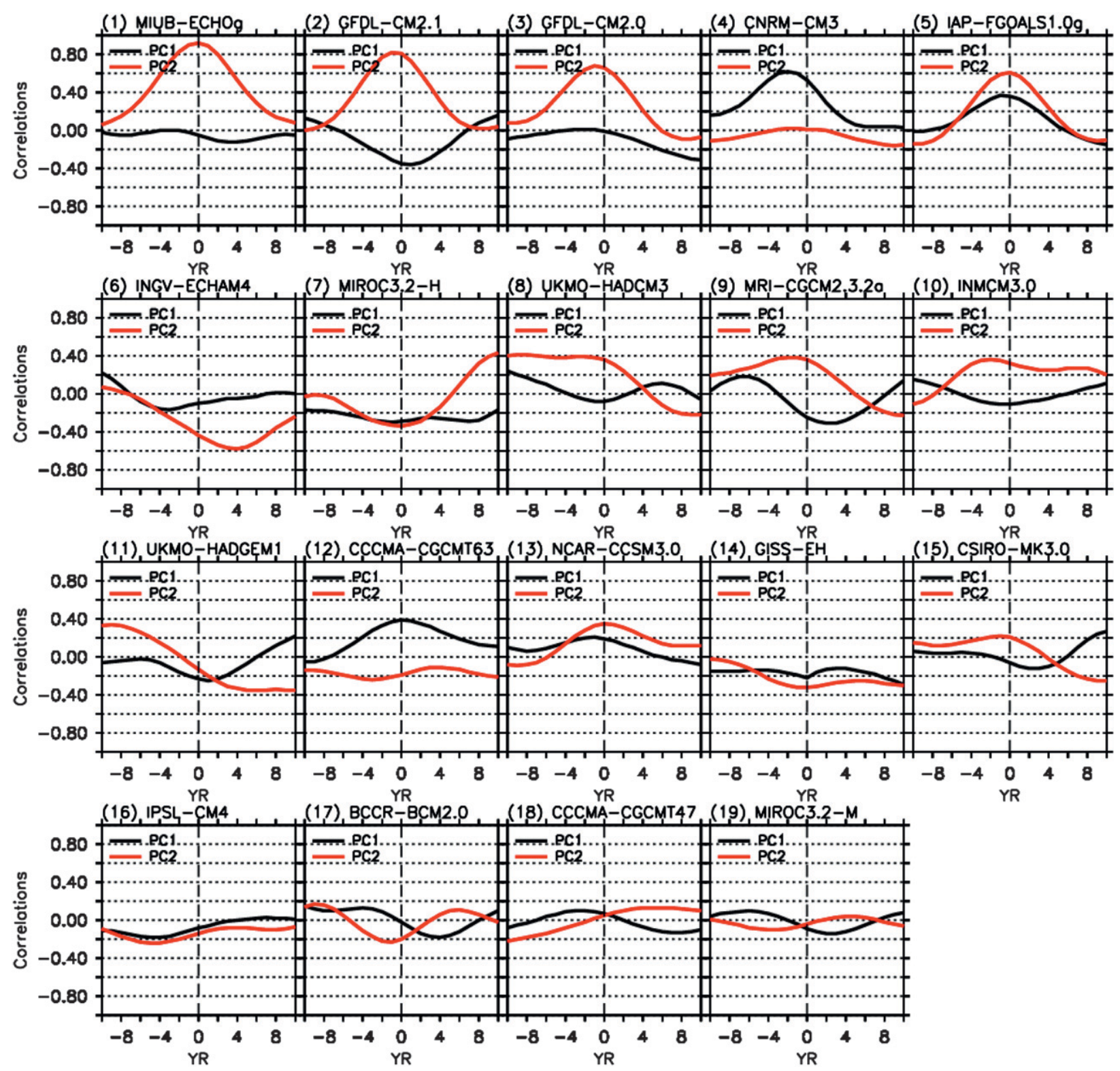

FIG. 4. Lead-lag $( \pm 10 \mathrm{yr})$ correlations between the square-rooted ENVF and the principal components of the first two leading EOFs of the tropical Pacific decadal ( $>10$ yr) variability.

occur during the positive phase of the principal component and weak events (blue circles) occur during the negative phase. We also show in Fig. 6 the percentage of strong ENSO events occurring in the positive phase of the decadal EOF mode (in the upper-right edge of each panel) and the percentage of weak ENSO events occurring in the negative phase of the EOF mode (in the lower-right edge of the panel). The percentages of both strong and weak ENSO are much larger than $50 \%$ for MIUBECHOg, GFDL CM2.0, and GFDL CM2.1. Figure 6 indicates that a cyclic modulation of ENSO intensity occurs in the CMIP3 models that produce the reversed spatial asymmetries. We also conducted similar analyses for the rest of the 16 CMIP3 models. The strong and weak ENSO events in these other models show a weaker tendency to favor particular phases of the leading modes of tropical Pacific decadal variability.

\section{Summary and discussion}

This study finds that the reversed spatial asymmetries between El Niño and La Niña identified in the observations also exist in CMIP3 preindustrial simulations. At least four CMIP3 models produce the reversed asymmetries 


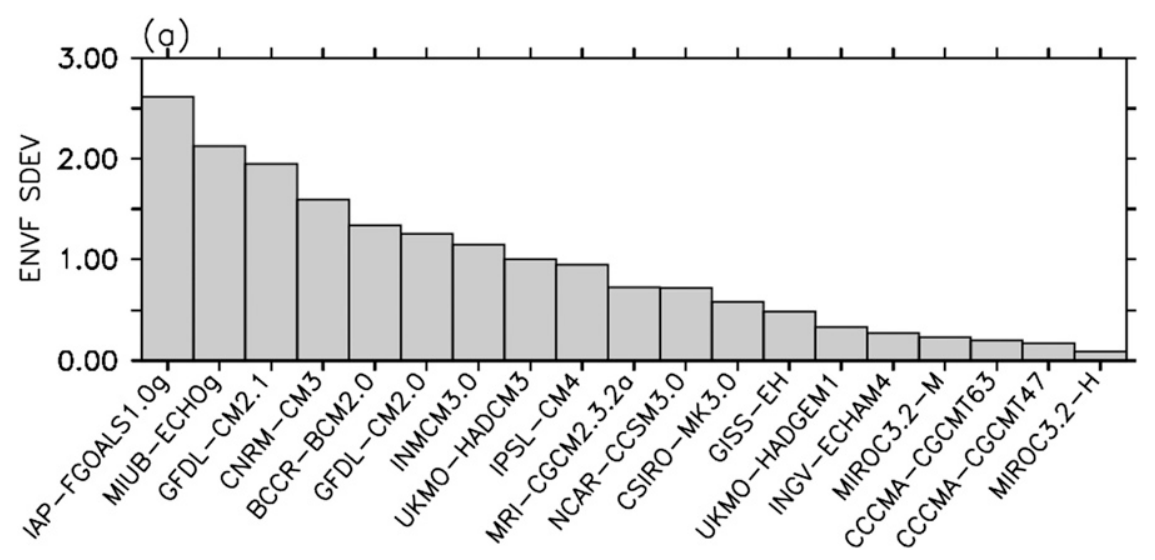

FIG. 5. Bar charts of standard deviations of the square-rooted ENVF from the 19 CMIP3 models.

with statistical significance. This study further examines the linkages among the reversed asymmetries, tropical Pacific decadal variability, and decadal ENSO modulation for the CMIP3 models in view of the ENSO-tropical Pacific interaction mechanism proposed by Sun and $\mathrm{Yu}$ (2009). It is concluded that three of the four CMIP3 models with the significant reversed asymmetries also produce a leading mode of tropical Pacific decadal SST variability resembling the residual effect of the El NiñoLa Niña asymmetries, and all of these three models produce strong decadal modulation in ENSO intensity. These results indicate that the ENSO-tropical Pacific interaction induced by the reversed El Niño-La Niña asymmetries is a plausible forcing mechanism for decadal modulation of ENSO intensity and that at least three CMIP3 models can be used for further studies of the ENSO-tropical Pacific interaction mechanism.

It is important to note that all of the three CMIP3 models (i.e., MIUB-ECHOg, GFDL CM2.0, and GFDL CM2.1) are among the CMIP3 models identified by $\mathrm{Yu}$ and Kim (2010) to realistically produce both the central Pacific (CP) and eastern Pacific (EP) types of ENSO, both of which were named by Kao and $\mathrm{Yu}$ (2009) to refer to tropical Pacific warming and cooling events occurring, respectively, near the central and eastern Pacific. This connection suggests that a realistic simulation of the two types of ENSO is required to produce the reversed spatial asymmetries in the CMIP3 models. Although not addressed in this study, how the reversed spatial asymmetries are produced may be found in some clues from some recent studies. It was suggested that the CP ENSO is excited by atmospheric forcing from the extratropics and grows locally at the equatorial Pacific via zonal ocean advection ( $\mathrm{Yu}$ et al. 2010) and that an EP El Niño (La Niña) event can excite sea level pressure variations in the extratropics that subsequently lead to a CP La Niña (El Niño) event (Yu and
Kim 2011). As a result, El Niño (La Niña) events in the eastern Pacific can be followed by La Niña (El Niño) events in the central Pacific. Such an extratropical channeling mechanism can lead to the spatial asymmetries between El Niño and La Niña. Choi et al. (2011) also

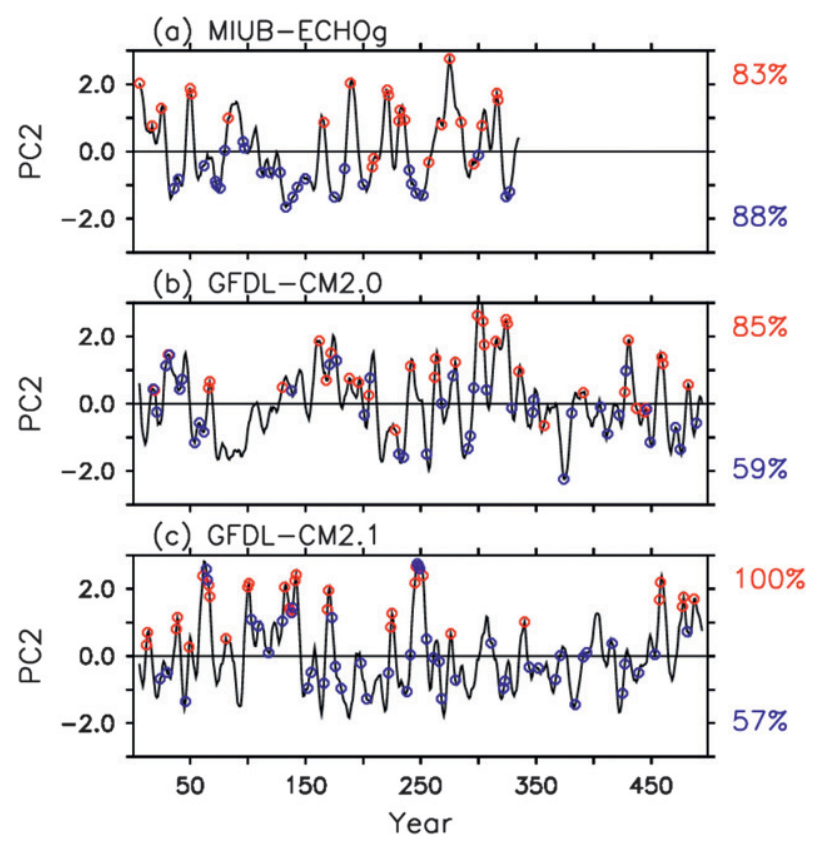

FIG. 6. Timing of the extreme $10 \%$ of the strong (red circles) and weak (blue circles) ENSO events from (a) MIUB-ECHOg, (b) GFDL CM2.0, and (c) GFDL CM2.1 superimposed onto the principal components (black lines) of their second EOF modes. A red (blue) circle indicates a strong (weak) ENSO event occurring at that particular year of the model simulation and is plotted on the principal component of the decadal EOF mode at that particular year. The percentage of strong (weak) ENSO events occurring in the positive (negative) phase of the principal component is shown at the upper-right (lower right) edge of (a)-(c). 
proposed a selection mechanism to suggest that the reversed spatial asymmetries might be produced as the coupling strength in the central and eastern tropical Pacific varies with tropical Pacific decadal variability. The three CMIP3 models identified in this study can be used for further investigations of these issues.

Acknowledgments. This research was supported by the National Science Foundation (ATM-0925396). The authors thank anonymous reviewers for their valuable comments. We acknowledge the modeling groups for making their model output available for analysis, the Program for Climate Model Diagnosis and Intercomparison (PCMDI) for collecting and archiving these data, and the World Climate Research Programme (WCRP) Working Group on Coupled Modelling (WGCM) for organizing the model data analysis activity. The WCRP CMIP3 multimodel dataset is supported by the Office of Science of the U.S. Department of Energy.

\section{REFERENCES}

An, S.-I., and B. Wang, 2000: Interdecadal change of the structure of the ENSO mode and its impact on the ENSO frequency. J. Climate, 13, 2044-2055.

_- and F.-F. Jin, 2004: Nonlinearity and asymmetry of ENSO. J. Climate, 17, 2399-2412.

Barnett, T. P., D. W. Pierce, M. Latif, D. Dommenget, and R. Saravanan, 1999: Interdecadal interactions between the tropics and midlatitudes in the Pacific basin. Geophys. Res. Lett., 26, 615-618.

Choi, J., S.-I. An, B. Dewitte, and W.-W. Hsieh, 2009: Interactive feedback between the tropical Pacific decadal oscillation and ENSO in a coupled general circulation model. J. Climate, 22, 6597-6611.

_ _ _ - J.-S. Kug, and S.-W. Yeh, 2011: The role of mean state on changes in El Niño's flavor. Climate Dyn., 37, 1205-1215, doi:10.1007/s00382-010-0912-1.

Dewitte, B., C. Cibot, C. Péigaud, S.-I. An, and L. Terray, 2007: Interaction between near-annual and ENSO modes in a CGCM simulation: Role of the equatorial background mean state. J. Climate, 20, 1035-1052.

Duan, W. S., H. Xu, and M. Mu, 2008: Decisive role of nonlinear temperature advection in El Niño and La Niña amplitude asymmetry. J. Geophys. Res., 113, C01014, doi:10.1029/2006JC003974.

Eckert, C., and M. Latif, 1997: Predictability of a stochastically forced hybrid coupled model of El Niño. J. Climate, 10, 14881504.

Fedorov, A. V., and S. G. Philander, 2000: Is El Niño changing? Science, 288, 1997-2002.

Frauen, C., and D. Dommenget, 2010: El Niño and La Niña amplitude asymmetry caused by atmospheric feedbacks. Geophys. Res. Lett., 37, L18801, doi:10.1029/2010GL044444.

Gu, D., and S. G. H. Philander, 1997: Interdecadal climate fluctuations that depend on exchanges between the tropics and extratropics. Science, 275, 805-807.

Hannachi, A., D. B. Stephenson, and K. R. Sperber, 2003: Probabilitybased methods for quantifying nonlinearity in the ENSO. Climate Dyn., 20, 241-256.
Hsieh, W. W., 2004: Nonlinear multivariate and time series analysis by neural network methods. Rev. Geophys., 42, RG1003, doi:10.1029/2002RG000112.

Kao, H.-Y., and J.-Y. Yu, 2009: Contrasting eastern-Pacific and central-Pacific types of El Niño. J. Climate, 22, 615-632.

Kirtman, B. P., and P. S. Schopf, 1998: Decadal variability in ENSO predictability and prediction. J. Climate, 11, 2804-2822.

Knutson, T. R., S. Manabe, and D. Gu, 1997: Simulated ENSO in a global coupled ocean-atmosphere model: Multidecadal amplitude modulation and $\mathrm{CO}_{2}$ sensitivity. J. Climate, 10, 131-161.

McCreary, J. P., and P. Lu, 1994: On the interaction between the subtropical and equatorial ocean circulation: The subtropical cell. J. Phys. Oceanogr., 24, 466-497.

McPhaden, M. J., and D. Zhang, 2002: Slowdown of the meridional overturning circulation in the upper Pacific Ocean. Nature, 415, 603-608.

Meehl, G. A., and Coauthors, 2007: The WCRP CMIP3 multimodel dataset: A new era in climate change research. Bull. Amer. Meteor. Soc., 88, 1383-1394.

Monahan, A. H., 2001: Nonlinear principal component analysis: Tropical Indo-Pacific sea surface temperature and sea level pressure. J. Climate, 14, 219-233.

Nakamura, H., and J. M. Wallace, 1990: Observed changes in baroclinic wave activity during the life cycles of low-frequency circulation anomalies. J. Atmos. Sci., 47, 1100-1116.

Newman, M., 2007: Interannual to decadal predictability of tropical and North Pacific sea surface temperatures. J. Climate, 20, 2333-2356.

— G. P. Compo, and M. A. Alexander, 2003: ENSO-forced variability of the Pacific decadal oscillation. J. Climate, 16, 3853-3857.

Penland, C., and P. D. Sardeshmukh, 1995: The optimal growth of tropical sea surface temperature anomalies. J. Climate, $\mathbf{8}$, 1999-2024.

Pierce, D. W., T. P. Barnett, and M. Latif, 2000: Connections between the Pacific Ocean tropics and midlatitudes on decadal timescales. J. Climate, 13, 1173-1194.

Rayner, N. A., D. E. Parker, E. B. Horton, C. K. Folland, L. V. Alexander, D. P. Rowell, E. C. Kent, and A. Kaplan, 2003: Global analyses of sea surface temperature, sea ice, and night marine air temperature since the late nineteenth century. J. Geophys. Res., 108, 4407, doi:10.1029/2002JD002670.

Rodgers, K. B., P. Friederichs, and M. Latif, 2004: Tropical Pacific decadal variability and its relation to decadal modulations of ENSO. J. Climate, 17, 3761-3774.

Schopf, P. S., and R. J. Burgman, 2006: A simple mechanism for ENSO residuals and asymmetry. J. Climate, 19, 3167-3179.

Smith, T. M., and R. W. Reynolds, 2004: Improved extended reconstruction of SST (1854-1997). J. Climate, 17, 2466-2477.

,$- \ldots$, T. C. Peterson, and J. Lawrimore, 2008: Improvements to NOAA's historical merged land-ocean surface temperature analysis (1880-2006). J. Climate, 21, 2283-2296.

Su, J., R. Zhang, T. Li, X. Rong, J.-S. Kug, and C.-C. Hong, 2010: Causes of the El Niño and La Niña amplitude asymmetry in the equatorial eastern Pacific. J. Climate, 23, 605-617.

Sun, D.-Z., and T. Zhang, 2006: A regulatory effect of ENSO on the time-mean thermal stratification of the equatorial upper ocean. Geophys. Res. Lett., 33, L07710, doi:10.1029/ 2005 GL025296.

Sun, F., and J.-Y. Yu, 2009: A 10-15-yr modulation cycle of ENSO intensity. J. Climate, 22, 1718-1735.

Timmermann, A., 2003: Decadal ENSO amplitude modulations: A nonlinear paradigm. Global Planet. Change, 37, 135-156. 
and F. F. Jin, 2002: A nonlinear mechanism for decadal El Niño amplitude changes. Geophys. Res. Lett., 29, 1003, doi:10.1029/2001GL013369.

Wang, B., and Y. Wang, 1996: Temporal structure of the Southern Oscillation as revealed by waveform and wavelet analysis. J. Climate, 9, 1586-1598.

Wang, C. Z., and R. H. Weisberg, 1998: Climate variability of the coupled tropical-extratropical ocean-atmosphere system. Geophys. Res. Lett., 25, 3979-3982.

Yeh, S. W., and B. P. Kirtman, 2004: Tropical Pacific decadal variability and ENSO amplitude modulation in a CGCM. J. Geophys. Res., 109, C11009, doi:10.1029/2004JC002442.
Yu, J.-Y., and S. T. Kim, 2010: Identification of central-Pacific and eastern-Pacific types of El Niño in IPCC-AR4 models. Geophys. Res. Lett., 37, L15705, doi:10.1029/2010GL044082.

_ and _ 2011: Relationships between extratropical sea level pressure variations and the central Pacific and eastern Pacific types of ENSO. J. Climate, 24, 708-720.

$\longrightarrow$, H.-Y. Kao, and T. Lee, 2010: Subtropics-related interannual sea surface temperature variability in the equatorial central Pacific. J. Climate, 23, 2869-2884.

Zhang, X. B., J. Sheng, and A. Shabbar, 1998: Modes of interannual and interdecadal variability of Pacific SST. J. Climate, 11, 2556-2569. 